Disponível em

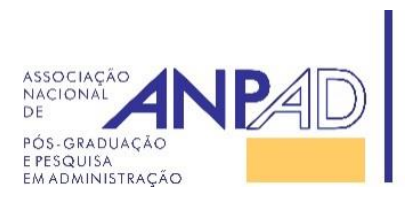

http://www.anpad.org.br/rac

RAC, Rio de Janeiro, v. 20, n. 5, art. 3, pp. 568-589, Set./Out. 2016

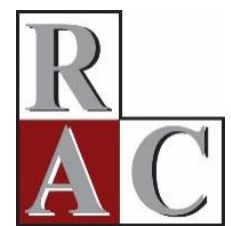

\title{
Regresso às Origens: A Importância do Indivíduo na Criatividade nas Organizações
}

Back to the Past: The Individual and its Role in Creativity in Organisations

Jorge Filipe da Silva Gomes ${ }^{1}$

Ana Filipa Rodrigues ${ }^{2}$

Ana Veloso ${ }^{2}$

Universidade de Lisboa ${ }^{1}$

Universidade do Minho ${ }^{2}$

Artigo recebido em 21.04.2015. Última versão recebida em 27.06.2016. Aprovado em 30.06.2016. Publicado online em 08.08.2016. 


\title{
Resumo
}

O objetivo deste texto é realçar o papel do indivíduo na criatividade nas organizações. Esse papel tem sido estranhamente remetido para um plano secundário, à medida que as modernas visões da criatividade a definem, sobretudo, com relação ao contexto em que ocorre. De fato, na perspectiva atual, a criatividade não pode ser entendida sem se considerarem os contextos funcional, relacional e organizacional nos quais está inserido o trabalhador. Tais são as considerações da maior parte dos autores que escreve sobre o tópico, como sejam Amabile (1996), Csikszentmihalyi (1996), ou, mais recentemente, Glăveanu (2010a, 2010b). Essa corrente dominante, com origem no interacionismo psico-social, tem ainda influenciado o desenvolvimento teórico de outros conceitos em psicologia, sociologia, e, na sequência, nas ciências sociais e humanas, e na gestão. Essa supremacia no que concerne a criatividade, tem conduzido os autores a olvidar o papel do indivíduo no processo e no resultado criativos, chegando a retirar-lhe a responsabilidade e o protagonismo pela geração e produção de ideias. Desse modo, no presente texto, recuperam-se os argumentos em favor da centralidade da pessoa na criatividade, defendendo-se que esta tem uma existência isolada de influências externas, e que, como tal, devem relembrar-se as bases individuais da criatividade.

Palavras-chave: criatividade; indivíduo; contexto; interacionismo psico-social.

\begin{abstract}
The goal of the current text is to highlight the role of the individual in creativity in organisations. This role has been strangely disregarded in recent years, as modern accounts of creativity have been emphasising the idea that creativity is only defined in context. This main stream argues that creativity is a process that essentially occurs within a functional, relational, and organisational context in which workers are inserted. Key authors defending such a position include the likes of Amabile (1996), Csikszentmihalyi (1996), and, more recently, Glăveanu (2010a, 2010b). This is a vision rooted in the psychosocial interactionist perspective, which has also had a considerable impact in other areas in psychology, sociology, management and other social and human sciences. This supremacy, with regards to creativity, has led many to forget the role of the individual person in the creative process and output, removing their responsibility and protagonism for generating and producing ideas. Hence, the current text intends to bring back to discussion the individual bases of creativity, that people can have an existence isolated from external influences, further defending that the concept can and should be defined out of context, rather than in context.
\end{abstract}

Key words: creativity; person; context; psychosocial interactionist. 


\section{Introdução}

O interesse pelo estudo da criatividade tem revelado um grande interesse nas últimas décadas. Na Encyclopaedia of Creativity (Runco \& Pritzker, 1999), a lista de tópicos tratados é extensa: criatividade na arquitetura ou na educação, relações entre criatividade e alcoolismo, os espíritos criadores de Bernard Shaw e Van Gogh, formação de climas criativos, entre outros. O Conselho e o Parlamento Europeu declararam 2009 como o Ano Europeu da Criatividade e Inovação. E, em 2013, em entrevista para o 16th PwC's Annual Global CEO Survey, o presidente executivo da multinacional EFACEC colocava a tônica do crescimento em uma aposta na inovação e na criatividade (Bento, 2013).

Porém, nem sempre parece ter sido assim. Piirto (2004) refere que a palavra criatividade apenas terá surgido recentemente. O termo ainda não existia em 1971 no Oxford English Dictionary, nem na edição de 1964 do American Heritage Dictionary of the American Language, ambos referências na língua inglesa. Segundo a autora, o vocábulo criatividade era motivo de cogitação já na filosofia clássica, mas teria sido introduzido na ciência psicológica com um discurso de Guilford, em 1950, perante a Associação Americana de Psicologia, e com um artigo de Stein, publicado em 1953 no Journal of Psychology. É precisamente a Stein (1953 como citado em Runco \& Jaeger, 2012) que se atribui a definição de criatividade, que hoje é aceita por investigadores de várias áreas disciplinares: criatividade é a geração de novas ideias que acrescentam valor e são úteis para alguma entidade.

A definição de Stein estabelece um novo paradigma de pensamento sobre criatividade, dado que desloca o foco da temática: este vai do indivíduo isolado criativo para a criatividade em contexto. Como que por contágio, a nova visão viria a inundar os textos e pesquisas sobre a matéria, assumindo que sem levar em linha de conta os múltiplos fatores contextuais, não é possível pensar de forma séria e profunda sobre criatividade. Como se verá adiante, a definição de Stein representa também uma socialização da criatividade, retirando-a do seu berço psicológico e conferindo-lhe um conjunto de atributos (valor e utilidade) essenciais num sistema social, alicerçado na troca entre indivíduos e na mercantilização de bens. Esta economia e socialização da criatividade foi recentemente reconhecida pelo sociólogo francês Menger (2014) na sua explicação dos mercados artísticos contemporâneos.

Todavia, a nova concepção de criatividade pode igualmente resultar num decréscimo do seu potencial transformador, dadas as características sancionadoras dos novos atributos (ilustradas, por exemplo, numa declaração como: se não é útil, não é criativo!). O caso de Mozart mostra o perigo: demasiadamente criativo e avançado para o seu tempo, viria a morrer com 35 anos, na miséria, e nunca tendo visto o seu trabalho reconhecido pela sociedade (Elias, 1991). Neste artigo, intenta-se recuperar o papel da individualidade em contexto, no que diz respeito à produção original e criativa. Assume-se, por conseguinte, a dissociação dos termos valor e utilidade, sistematicamente presentes na visão de contexto, da produção original e criativa. $\mathrm{O}$ artigo tem ainda um segundo objetivo: o de apresentar uma breve e condensada revisão do conceito de criatividade em contexto.

\section{A Noção de Criatividade}

\section{A criatividade na história}

$\mathrm{Na}$ antiguidade, acreditava-se que a criatividade tinha uma origem extraordinária, que era uma dádiva dos deuses a alguns eleitos (Albert \& Runco, 1999), e que a criação resultava de inspiração divina ou mística. Os antigos afiançavam que o cérebro humano se dividia em duas câmaras: numa delas, os deuses cultivavam as novas ideias, enquanto a outra metade recebia essas ideias e transformava-as em obras humanas. A criatividade era, pois, lavrada no cérebro pelos deuses, que se entretinham criando imagens para serem usadas pelas pessoas. Aristóteles foi o primeiro a questionar esse modelo, mas não tendo aprofundado o assunto, o modelo das duas câmaras persistiu durante mais alguns séculos. 
O conceito de gênio surge no Renascimento, assim como a ideia de que a genialidade e a criatividade são fenômenos espirituais e sobrenaturais, e largamente hereditários. Apenas a partir do século XVIII essas visões metafísicas e místicas começam a ser abandonadas, passando-se a acreditar que o gênio nada tem de sobrenatural, embora tenha persistido a ideia de que existe uma excepcionalidade no indivíduo gênio e criativo. Com Darwin, no século XIX, surge a noção de que criatividade é uma das capacidades adaptativas dos seres vivos; no ser humano, a criatividade é uma das ferramentas para a resolução de problemas objetivos, através de seleções e adaptações bem sucedidas e, por isso, perduráveis. Essa visão confere à criatividade um lugar de destaque na própria vida. Os primeiros estudos científicos da criatividade surgem na psicologia, com Binet e Galton: depois de uma primeira fase em que se olha, sobretudo, para a pessoa, na crença de que os criativos são determinados pela genética, os modelos posteriores começam a olhar para o exterior do indivíduo e, concretamente, para a influência de fatores externos, como a família e a educação (Albert \& Runco, 1999).

A equiparação com a genialidade perduraria alguns anos, mormente a associação entre criatividade e loucura. Estudos conduzidos nos anos de 1990 confirmaram que grandes artistas, como Van Gogh e Virgínia Wolf sofreram de males psicológicos mais ou menos graves, como o transtorno bipolar. Martindale (1990) estudou 21 poetas ingleses e 21 franceses, que viveram entre 1670 e 1909, e concluiu que de 40 a $55 \%$ sofreram de psicopatologias graves. Kaufman (2005), em um estudo realizado com escritores, concluiu que os poetas apresentam uma maior probabilidade de sofrer de doença mental do que outros tipos de escritores. Ko e Kim (2008) analisaram 76 gênios científicos e confirmaram que a existência de alguma forma de psicopatologia tem um papel moderador na relação entre contribuição criativa e eminência científica. Um estudo realizado na Suécia, com artistas e cientistas, demonstrou que as pessoas que exercem profissões criativas não apresentam uma maior probabilidade de sofrerem de psicopatologia; todavia, o mesmo estudo também mostrou que os escritores têm um maior risco de desenvolver problemas como esquizofrenia, perturbação bipolar, depressão ou ansiedade (Kyaga et al., 2012).

Essa incongruência de resultados tem sido motivo para algumas explicações. Baer (2012) elucida que a criatividade, em boa parte dos estudos, tem sido considerada como um domínio geral, e, por conseguinte, não podem ser generalizados os resultados obtidos. $\mathrm{O}$ autor observa que, enquanto nas artes se verifica uma associação entre criatividade e doença mental, em outros domínios, como nas ciências, não se constata tal relação. E mesmo nas artes podem existir diferenças significativas nos resultados.

\section{A criatividade em contexto}

A partir dos anos de 1950, começa a formar-se a ideia de que, para se julgar algo criativo, tornase necessário enquadrar a produção original em um quadro mais alargado de análise. Particularmente a partir dos anos de 1970 e 1980, com a emergência da perspectiva do interacionismo psico-social nas ciências sociais e humanas, ganha sobeja relevância o ambiente no qual a criatividade se materializa. Em 1999, Ryhammar e Brolin declaram, lapidarmente, que a criatividade é um fenômeno que não pode ser compreendido fora de um "sistema mais vasto de redes sociais, domínios de problemas e campos de atuação" (p. 268).

A revolução no pensamento sobre criatividade, ocorrida a partir dos anos 50, compreende-se no âmbito de uma dinâmica de mudança mais vasta, em que a modernidade herda um individualismo assente na liberdade e na igualdade, e em que o valor dos homens não deriva da sua posição na sociedade, e sim do valor que são capazes de gerar em tal sociedade (Dumont, 1985; Stolcke, 2001). Para gerar esse valor, torna-se necessário quantificar as diferenças que existam entre as capacidades dos homens, e tornar transacionáveis os produtos de tais capacidades (Menger, 2014; Simmel, 1998). Essa evolução rompe com a ideia de que a criatividade tem um valor intrínseco, isento de juízos externos, e faz depender esse valor do contexto no qual se manifesta, ou seja, do seu produto visível. Simultaneamente, o novo paradigma impele o indivíduo a levar em conta os produtos criativos no tempo presente, sendo pouco importante considerar o potencial de tais produtos no futuro. 
Sternberg e Lubart (1999) seguem a nova corrente, e anotam que o contexto envolvente afeta a produção criativa de várias formas: (a) o grau em que favorece a geração de novas ideias; (b) a intensidade do encorajamento e do suporte ao desenvolvimento das ideias criativas e subsequentes produtos tangíveis; e (c) a avaliação do produto criativo. Ao se refletir nos fatores organizacionais que afetam a criatividade individual e de grupos, revela-se útil distinguir entre fatores genéricos e específicos. Os primeiros são aqueles que influenciam todos os indivíduos de uma forma similar, enquanto os segundos são aqueles que os influenciam de modos particulares e associados a grupos bem localizados. Entre os primeiros, são aqui detalhados a família, a educação formal e o sistema sociocultural. No segundo grupo são incluídos os fatores que, em uma organização, agem sobre a ação criativa dos indivíduos.

\section{Contexto genérico: família, educação e sistema sociocultural}

A família é um estruturador essencial para a personalidade humana (Almagro, 1986). Afeta a criatividade e a imaginação, sendo central o papel dos pais (Alencar \& Fleith, 2003). Para essas autoras, a personalidade dos pais exerce uma influência profunda, e, de forma concreta, as atitudes e as expectativas em relação à criança. Também o nível de confiança na capacidade da criança, de ser responsável, explorar o mundo, o respeito pelos seus sentimentos e fantasias, influenciam o seu potencial criador. A forma como os pais encaram e lidam com os erros dos filhos afeta negativamente os seus comportamentos criativos futuros, reduzindo a probabilidade de proporem soluções originais e disruptivas para os problemas que enfrentam.

Outro mecanismo descrito na literatura (e.g. Amabile, 1996) é a modelação (apelidado imitação de adultos, por Chávez-Eakle, Eakle, \& Cruz-Fuentes, 2012); os pais modelam os filhos nas suas mais variadas dimensões. A modelação também existe fora da família, como nota Amabile, ao referir-se aos professores e mentores que acompanham o crescimento da pessoa desde a infância até o estado adulto. Morais (2001) resume vários estudos nos quais ambientes familiares diversos conduzem a diferentes desempenhos criativos das crianças. Entre os vários exemplos, a autora menciona a maior manifestação de pensamento criativo no filho primogênito, a maior capacidade de realização por parte de filhos únicos, a ocupação profissional dos pais, e a elevada criatividade em crianças educadas na religião judaica. Todavia, a autora conclui que essas pistas são insuficientes para prescrever o lar ideal que garanta o desenvolvimento do sujeito criativo.

No que concerne à educação formal, numa apresentação em 2006 para a TED, Ken Robinson revelou os seus pontos de vista sobre a interferência negativa que a educação formal e padronizada tem sobre a criatividade das crianças e adolescentes (ver também Robinson, 2001). Segundo o especialista, o sistema formal de educação foi desenhado para desenvolver nos educandos um pensamento abstrato, racional e lógico, característico dos professores acadêmicos, que, desse modo, exclui tipos de pensamento criativo, presentes nos músicos, nos bailarinos ou nos pintores. Nessa linha de pesquisa, Maker, Jo e Muammar (2008) acompanharam, durante três anos, 2000 alunos de escolas primárias, a fim de observar os efeitos de um programa alternativo de aprendizagem sobre o desenvolvimento da criatividade. Confirmaram que a criatividade se desenvolve através de atividades que apoiem a aprendizagem ativa, o acesso a escolhas variadas, a exploração, a autoavaliação e a busca e a resolução de problemas. Também Chávez-Eakle, Eakle e Cruz-Fuentes (2012) afirmam que a pressão sentida por estudantes para alcançarem um bom desempenho em testes padronizados é desfavorável à criatividade, erodindo elementos que podem ser relevantes para a produção original nos primeiros anos escolares. No mesmo sentido, Sternberg (2012) critica a parca contribuição da escola para a criatividade dos alunos tanto pela forma como estes são avaliados como também pela maneira como os professores são forçados a apresentar resultados com base em testes que privilegiam o pensamento convergente. $\mathrm{O}$ autor sublinha que os testes em si não são bons nem maus, mas antes limitados na forma como avaliam o conhecimento dos alunos, promovendo o desenvolvimento de perspectivas acríticas e pouco criativas.

Talvez o que deva ser repensado em termos de educação formal não é tanto a formação orientada para a formalização, a padronização e o sucesso num determinado modelo de mundo, e sim o equilíbrio entre a necessária preparação para viver nesse modelo, por um lado, e a possibilidade de transformar e 
criar um mundo diferente, por outro. Feldman (1999) enuncia esse paradoxo formulando várias questões: qual a melhor sequência de experiências?, quão rígida deve ser a disciplina?, quando é que o trabalho deve ser sujeito à crítica?, qual o ponto em que a pessoa atingiu os limites conferidos pela preparação orientada?. Esta última questão é particularmente relevante, sobretudo se se atentar aos modelos de criatividade de Csikszentmihalyi e de Amabile, em que um indivíduo é mais criativo após ter alcançado conhecimento suficiente no seu domínio de atividade.

Uma educação que contrabalance criatividade com padronização pode ser conseguida se outros meios de socialização estiverem presentes no desenvolvimento da criança. Com efeito, se, numa fase inicial do seu crescimento, a criança é sujeita à influência da família, ao entrar na escola ela alarga o seu mundo de relações, encetando ligações especiais com os amigos e com outros educadores (Sousa, 2000). $\mathrm{Na}$ adolescência, a base alarga-se ainda mais, emergindo os grupos de pares, professores, grupos associativos, desportivos, etc. Como mostra Gardner (1993 como citado em Piirto, 2004), a emergência da obra criativa surge frequentemente no seio de grupos, através do reforço mútuo e do reconhecimento primário entre os pares. Picasso, por exemplo, não estava só no movimento cubista. Braque, outro cubista, acompanhou o seu famoso amigo espanhol no rompimento com modos mais tradicionais de olhar para a pintura.

O último fator genérico é o sistema sociocultural. Nas últimas décadas, as teorias individualistas da criatividade foram substituídas por perspectivas que valorizam o contexto sociocultural (Glăveanu, 2010a). A criatividade começa, assim, a ser entendida como um processo que ocorre num contexto de interação social (Aggarwal \& Bhatia, 2011), pois as competências dos indivíduos inerentes à criatividade são validadas e julgadas pelos outros, que, por sua vez, também estão envolvidos em um contexto cultural específico. Glăveanu (2010b), um dos expoentes mais recentes nesse domínio, afirma que a "criatividade nunca é uma atividade isolada" (p. 61). Para o autor, criatividade e cultura são elementos interdependentes, pelo que todas as manifestações criativas constituem uma forma de participação cultural, pois utilizam elementos culturais para formar ou transformar o que é novo.

Lubart (1999) tinha já afirmado que a concepção de criatividade é distinta entre culturas. Nas culturas ocidentais, criatividade é, sobretudo, sinônimo de produto observável, valorizado e útil. Por contraste, nas culturas orientais, criatividade não está relacionada com a existência de produtos criativos, e sim com um estado transcendental do ser, uma ligação a uma condição primordial, uma expressão de uma essência interior. É um meio crucial para se conseguir atingir um estado superior de existência, pois ajuda a visionar a exata natureza do self, de um objeto ou de um acontecimento. No Hinduísmo, por exemplo, a criatividade é uma expressão espiritual e religiosa, não uma solução inovadora para um problema.

Uma noção em que o contexto assume particular relevância é o de cidades criativas (Landry, 2000), a qual preconiza a transformação dos espaços urbanos no sentido de oferecer melhores condições para os cidadãos pensarem e agirem com imaginação. Apenas assim, segundo o autor, poder-se-ão resolver os problemas que contaminam as cidades atuais. Criar uma cidade criativa implica não apenas uma mudança no plano de estruturas físicas (o hardware), mas também no plano das estruturas culturais (o software). Termos posteriores surgiram na literatura, incluindo indústrias criativas, classes criativas e economia criativa.

Csikszentmihalyi (1996) defende que a criatividade é um processo sistêmico sustentado por um modelo no qual se cruzam três componentes: a pessoa (bagagem genética e experiências pessoais), o domínio (cultura) e o campo (sistema social), definido como a organização social do domínio. Conforme asseveram Alencar e Fleith (2003), uma ideia original pode ser rejeitada se o campo for do gênero defensivo, ou se fizer parte de um sistema social que desincentive a criatividade ou em que não exista interesse em trazer novidades para o domínio. As autoras concluem que, nesses casos, cabe ao autor da ideia convencer o campo de que a sua ideia ou produto tem valor e deve ser incluída no domínio.

Para Simonton (1999), o indivíduo cria impulsionado pelas suas motivações, ao que se segue uma aproximação ao meio com o propósito de procurar formas de relacionamento de cariz artístico, científico ou intelectual. Posteriormente, esse todo converge para o sistema sociocultural de que decorre - ou não 
- a sua assimilação e reconhecimento. Desse modo, e apesar dos atributos da pessoa criativa, a manifestação de criatividade vai depender sempre do tempo e do espaço em que se insere, isto é, do zeitgest, ou do ortgeist. É assim que uma ideia ou realização pode ser julgada como não criativa em um dado momento ou lugar, e criativa no futuro ou em outro local (ou vice-versa); tal sucede porque os critérios de interpretação e julgamento mudam com o tempo e com o espaço (Elias, 1991; Feldman, 1999). Exemplos dessas diacronias abundam na história: J. S. Bach morreu em 1750, quase desconhecido à altura; as suas obras apenas foram recuperadas no primeiro quartel do século XIX, e, hoje, ninguém questiona a genialidade do maior compositor do período Barroco (Morais, 2001). Como exposto na parte inicial deste texto, o mesmo terá ocorrido a W. A. Mozart, um gênio reconhecido apenas após a sua morte (Elias, 1991). Este ponto será retomado adiante.

\section{Contexto específico: organização}

A criatividade tem sido particularmente discutida nas organizações, dada a sua influência sobre a capacidade inovadora das empresas, o empreendedorismo e a mudança (Aggarwal \& Bhatia, 2011). Não admira, por conseguinte, que as organizações hodiernas dediquem tantos esforços à identificação dos fatores que bloqueiam a criatividade e a inovação, aos concursos de ideias, à aplicação de técnicas de estimulação do pensamento divergente ou à contratação dos serviços de entidades externas, a fim de melhorarem a criatividade dentro delas. Os fatores relacionados com a criatividade nas organizações têm sido reconhecidos por um imenso rol de autores (e.g., Amabile, 1996; Csikszentmihalyi, 1996; Ekvall, 1996; Hunter, Bedell, \& Mumford, 2007; Isaksen \& Lauer, 2002). Pela simplicidade, atualidade e síntese provida, o trabalho empírico de Alencar e Bruno-Faria (1997) é aqui escolhido para expor de forma breve os agentes organizacionais que influenciam a criatividade. Vários outros trabalhos existem que reproduzem muitos desses agentes (e.g. Aggarwal \& Bhatia, 2011; Coelho, Augusto, \& Lages, 2011; Dul \& Ceylan, 2011; Joo, McLean, \& Yang, 2013). As autoras os decompõem em promotores (Tabela 1) e inibidores da criatividade (Tabela 2).

Tabela 1

\section{Agentes Promotores da Criatividade nas Organizações}

\begin{tabular}{ll}
\hline Nome do agente promotor & Descrição \\
\hline $\begin{array}{l}\text { Desafio das tarefas e objetivos } \\
\text { desafiantes }\end{array}$ & $\begin{array}{l}\text { Se a natureza e o conteúdo do trabalho demandarem criatividade, então é } \\
\text { mais provável que as pessoas exibam ideias criativas. Esse é um fator-chave, } \\
\text { dada a sua relação com a motivação intrínseca. }\end{array}$ \\
\hline $\begin{array}{l}\text { Apoio dos colegas e do grupo } \\
\text { de trabalho }\end{array}$ & $\begin{array}{l}\text { Os colegas e o grupo de trabalho fornecem um espaço onde circulam o } \\
\text { diálogo, a confiança e a comunicação, e, por conseguinte, são potenciais } \\
\text { indutores de estimulação de ideias novas. É uma dimensão do ambiente em } \\
\text { que a concepção da criatividade como um processo social está } \\
\text { particularmente patente. }\end{array}$ \\
\hline $\begin{array}{l}\text { Liberdade e autonomia para } \\
\text { tomar decisões sobre o trabalho }\end{array}$ & $\begin{array}{l}\text { A liberdade e a ausência de constrangimentos é um predicado básico para a } \\
\text { criatividade, uma vez que esta pressupõe a geração do maior número possível } \\
\text { de ideias novas para a solução de um problema, pelo que os sujeitos }\end{array}$ \\
produtores dessas ideias devem ter liberdade para pensar e agir.
\end{tabular}


Tabela 1 (continuação)

\begin{tabular}{ll}
\hline Nome do agente promotor & Descrição \\
\hline Ambiente físico & $\begin{array}{l}\text { Um ambiente agradável, espaçoso, luminoso, ventilado e com equipamentos } \\
\text { adequados promove a criatividade. }\end{array}$ \\
\hline Salários e benefícios & $\begin{array}{l}\text { Dimensão que respeita a motivação extrínseca. Salários e benefícios } \\
\text { percebidos como condignos e justos estimulam a produção criativa. }\end{array}$ \\
\hline Apoio dos chefes & $\begin{array}{l}\text { Abertura, flexibilidade, respeito por opiniões divergentes e estímulo pela } \\
\text { procura de soluções novas. O papel das chefias é identificado como um fator } \\
\text { importante para a criatividade por uma longa série de outros autores. }\end{array}$ \\
\hline $\begin{array}{l}\text { Recursos tecnológicos e } \\
\text { materiais }\end{array}$ & $\begin{array}{l}\text { Disponibilidade de equipamentos e materiais que facilitem o } \\
\text { desenvolvimento de novas ideias. }\end{array}$ \\
\hline Treino e formação & $\begin{array}{l}\text { Disponibilidade de programas de treino para todo o pessoal com o propósito } \\
\text { de desenvolver o seu potencial criativo e de facilitar o processo de inovação. }\end{array}$ \\
\hline
\end{tabular}

Tabela 2

Agentes Inibidores da Criatividade nas Organizações

\begin{tabular}{|c|c|}
\hline Nome do agente inibidor & Descrição \\
\hline Chefia & $\begin{array}{l}\text { Um chefe descrito como não sendo receptivo às novas ideias e produções dos } \\
\text { indivíduos ou distante dos seus colaboradores. }\end{array}$ \\
\hline $\begin{array}{l}\text { Falta de equipamentos e de } \\
\text { outros materiais }\end{array}$ & $\begin{array}{l}\text { Falta ou escassez de recursos, tornando difícil a execução das tarefas, o que } \\
\text { conduz as pessoas a gastarem o seu tempo a criarem formas de resolver os } \\
\text { seus problemas de falta de recursos, ao invés de investirem tempo e energia } \\
\text { em gerar novos produtos ou ideias. }\end{array}$ \\
\hline Falta de treino e de formação & $\begin{array}{l}\text { Falta de treino para a expansão das competências necessárias para a boa } \\
\text { realização das tarefas. }\end{array}$ \\
\hline Cultura organizacional & $\begin{array}{l}\text { Uma organização que se caracterize pela renúncia a novas ideias, que não } \\
\text { apoia a assunção de riscos, que cultive uma ideia de medo perante situações } \\
\text { de erro e que se mostre resistente a mudanças. }\end{array}$ \\
\hline Estrutura organizacional & $\begin{array}{l}\text { Uma estrutura rígida, burocrática, autoritária, com normas rígidas, que tenha } \\
\text { sistemas de penalizações duros, com muitas hierarquias, com poder } \\
\text { centralizado e com falta de objetivos claramente definidos. }\end{array}$ \\
\hline $\begin{array}{l}\text { Relações pessoais e grupo de } \\
\text { trabalho }\end{array}$ & $\begin{array}{l}\text { Falta de diálogo e de atividades de grupo, falta de confiança entre os } \\
\text { colaboradores, não aceitação de novas ideias por parte dos colegas e conflitos } \\
\text { frequentes entre eles. }\end{array}$ \\
\hline Ambiente físico & $\begin{array}{l}\text { Ambiente físico inadequado, seja devido à existência de ruídos, de calor } \\
\text { excessivo, de iluminação insuficiente, de falta de espaço ou de outros fatores. }\end{array}$ \\
\hline $\begin{array}{l}\text { Influências políticas e } \\
\text { administrativas }\end{array}$ & $\begin{array}{l}\text { Mudanças frequentes de políticas que implicam alterações no modo de } \\
\text { funcionamento da organização e que alterem ou redirecionem os objetivos ou } \\
\text { a missão da organização. }\end{array}$ \\
\hline Salários e benefícios & $\begin{array}{l}\text { Sistemas de remuneração desadequados, com salários baixos e políticas de } \\
\text { remuneração que não recompensem de uma forma justa o trabalho criativo. }\end{array}$ \\
\hline Características da tarefa & Tarefas repetitivas, que não sejam desafiantes e que sejam muito rotineiras. \\
\hline Volume de trabalho & Excesso de trabalho e pressão para terminá-lo. \\
\hline
\end{tabular}

Essas listas de agentes complicam a equação da criatividade nas organizações. Com efeito, tais fatores contextuais tornam muito difícil a descoberta de uma combinação única para explicar a 
criatividade em ambientes empresariais. Ilustram ainda os argumentos centrais das modernas concepções de criatividade em contexto: a criatividade não existe em um vácuo e o indivíduo criativo está condicionado, na sua atividade criadora, pelo contexto onde se insere. Pode ser um destruidor de paradigmas vigentes e do status quo de qualquer contexto conhecido, pode ser um revolucionário e um inspirador de criações profundas, ou pode simplesmente ser alguém que propõe novas formas, novas ideias e novos pensamentos. Em qualquer caso, os condicionalismos contextuais impõem uma ditadura panóptica do qual não há escape possível e, muitas vezes, sequer haja consciência da sua existência. No quadro da indústria criativa, Menger (2014) explica que os artistas que têm sucesso são os que são percebidos pela comunidade artística (professores de arte, críticos, comerciantes de arte, etc.) como os mais valiosos, num processo contínuo de comparação competitiva.

Mas, ao mesmo tempo, a exacerbação do papel do contexto fez de algum modo esquecer que, no centro do mesmo, existe a pessoa com capacidades criativas, que é o motor ou a chama que põe em andamento todo e qualquer processo criativo e de inovação. A seção seguinte recupera a discussão centrada no indivíduo criativo.

\section{Regresso às Origens da Criatividade}

\section{Criatividade em contexto e criatividade fora de contexto}

Como se conclui da seção anterior, não é fácil compreender o que se encontra na base da criatividade humana. Qualquer exercício com esse intuito resulta em algo que tem tanto de contestável quanto de inconsequente. Com efeito, se pode-se afirmar que os avanços dos últimos cem anos põem de lado explicações quixotescas do que são pessoas criativas (e.g. ter cabelos ruivos é sinal de genialidade, visto que o cabelo ruivo é mais irrigado por sangue, Brad, 1829 como citado em Friedel, 1992), também é possível dizer que as várias correntes da Psicologia assemelham-se a um quebra-cabeças, com dezenas de peças importantes, para explicar o que é a criatividade e de que se origina. Mais grave, ainda, é que essas peças interagem entre si, assim como interatuam com os ambientes onde estão imersas, produzindo uma combinação infinita de situações que reduzem as tentativas de classificação a um mero exercício acadêmico. Encontrar o perfil do indivíduo criativo pode, de fato, nunca ser possível de conseguir.

E, todavia, parece lógico afirmar que algumas pessoas são mais criativas do que outras, independentemente dos ambientes e contextos em que estejam inseridas. Em um curioso livro publicado em 2012, Cain surge em defesa de pessoas introvertidas e do potencial criativo que emerge por se experienciar algum isolamento social ou mesmo a solidão. A criatividade e a produtividade não derivam, por conseguinte, apenas de ambientes ricos em socialização, mas também de situações em que as pessoas pouco interagem com os seus meios envolventes. A autora dá os exemplos de Darwin, que meditava enquanto caminhava pelo bosque e evitava ir a festas, e de Wozniak, que desenhou o primeiro computador Apple na solitude do seu gabinete na Hewlett-Packard. As sociedades orientais, relembra a mesma autora, realçam o valor da vida contemplativa e meditativa para a evolução, ao invés das dinâmicas sociais e coletivas, centrais na visão interacionista (ver também Lubart, 1999). Também na sua obra paradigmática redigida a partir de reflexões realizadas sobre os sobreviventes dos campos de concentração nazistas, Frankl (2004) chama atenção para a capacidade que alguns indivíduos têm em manter o livre arbítrio e a capacidade para assumir livremente escolhas fundamentais (como abandonarse ou não ao destino quase fatal em um campo da morte), não obstante os piores ambientes vivenciados.

Os estudos sobre inspiração e intuição, dois mecanismos correlatos da criatividade, mostram que estes ocorrem largamente sem intervenção de condicionantes exteriores (Bowers, Regehr, Balthazard, \& Parker, 1990; Claxton, 1998). O próprio comportamento improvisado (Cunha, 2002), apesar de emergir enformado pelo contexto específico, vivido pelo indivíduo, parece ser dependente mais de capacidades individuais do que de alguma interação que a pessoa entabule com o seu contexto. 
O contexto é, sem dúvida, um importante elemento no entendimento da criatividade, seja em ambientes organizacionais ou outros, mas a saliência que lhe foi dada, em anos recentes, conduziu a uma minimização do papel do indivíduo criador e à elaboração de quadros teóricos que aparentam pesar mais o papel do contexto do que o da pessoa. Joo, McLean e Yang (2013) parecem reconhecer essa minimização do indivíduo ao contrariar a tendência e propõem um modelo integrativo de criatividade, em que os fatores individuais são recuperados e até realçados face aos fatores contextuais. De forma análoga, e não obstante enfatizando o papel do contexto organizacional, Gomes, Rodrigues e Veloso (2015) assumem que o contexto pode ocasionalmente ter um efeito neutro na estimulação da criatividade e dos produtos criativos.

O papel sancionador do contexto na avaliação da produção criativa (visto e.g. em Csikszentmihalyi, 1996) não está aqui colocado em causa, e sim o seu papel de coprodutor na obra criativa (visto e.g. em Amabile, 1996). Ou seja, defende-se que a produção criativa (seja ela o pequeno c ou o grande C) não requer necessariamente uma coprodução entre o indivíduo e o seu contexto externo envolvente; pelo contrário: a mera existência de um contexto pode ser um fator contraproducente para a gênese criativa, como ilustram os casos já referidos de Bach e Mozart (e de muitos outros).

No remanescente deste texto, apresentam-se as bases individuais da criatividade, com vista a realçar-se o valor da pessoa para a geração criativa, isolada do seu contexto.

\section{Bases individuais da criatividade}

Expõem-se aqui as principais dimensões individuais com mais impacto sobre a produção criativa, em ambiente de trabalho. Apesar do estado atual do conhecimento sobre a matéria ser algo profuso, disperso e até incongruente, é possível observar que alguns aspectos emergem sistematicamente na literatura, sendo esses que são, em seguida, apresentados.

\section{Variáveis biográficas}

Encontrar uma relação entre a cor do cabelo e a criatividade pode parecer obtuso, todavia, a literatura é profícua em mostrar outras relações inopinadas. Por exemplo, pesquisas que utilizam a historiometria revelam que cientistas do main stream e compositores clássicos são geralmente primogênitos, enquanto cientistas revolucionários e escritores criativos são, principalmente, segundos ou terceiros-filhos (Schachter, 1963 como citado em Simonton, 1999). A comprovação dessas ligações parece ser discussão encerrada, mas falta explicar porque ocorrem.

A idade aparenta ser a variável mais estudada em relação com a criatividade. A grande questão é: são as pessoas mais velhas menos criativas? Vários anos de investigações demonstram que a relação entre a idade e a criatividade possui a forma de um $\mathbf{J}$ invertido (Simonton, 1999), e depende das áreas que se nomeiem. Assim, o pico criativo será atingido entre os 25 anos e os 30 anos para Poesia Lírica, Matemática, Química e Física; entre os 30 e os 40 para a Psicologia e Ciências Sociais; entre os 30 e os 40 para a Arquitetura e Literatura; mas na Filosofia, a criatividade ocorre apenas aos 60 anos.

Uma última variável que suscita atenção é o gênero. Aqui os estudos são inconclusivos, atribuindo ora a mulheres ora a homens o epitáfio de mais criativo. $\mathrm{O}$ fato de, em termos numéricos absolutos, serem os homens que pontuam mais nas artes em termos de obra feita, não significa que o homem é mais criativo. A questão da representação do papel sexual, dos estereótipos, da cultura ou da própria personalidade, contaminam e influenciam bastante o desempenho dos sexos na criatividade. Por exemplo, no estudo de Stoltzfus, Nibbelink, Vredenburg e Thyrum (2011) observou-se que tanto os participantes homens quanto mulheres que se identificam com as características do papel de gênero oposto, apresentam níveis mais elevados de criatividade. Resultado semelhante foi obtido por Proudfoot, Kay e Koval (2015), num experimento sobre estereótipos de gênero e criatividade. Esses trabalhos mostram que o conceito de identificação com o papel de gênero exerce influência sobre a criatividade do indivíduo. 


\section{Inteligência}

A relação entre estes dois construtos não é fácil de determinar. De uma forma geral, os estudos mostram que, acima de um nível médio a elevado de inteligência, não existe relação entre os dois construtos (Amabile, 1996). Ou seja, até certos níveis de inteligência, confirma-se que maior inteligência é sinal de maior criatividade. Mas, a partir de certo nível de inteligência, essa relação deixa de existir. Porém, nem sempre os resultados de estudos empíricos confirmam essas proposições. Por exemplo, Furnham e Bachtiar (2008) não encontraram qualquer associação significativa entre as várias formas de medição da criatividade que utilizaram em seu trabalho, e o Wonderlic Personnel Test (uma prova de inteligência); ao invés disso, a personalidade emergiu como um forte preditor da criatividade (ver alínea seguinte). Também Silvia (2008) evidenciou que os dois conceitos (isto é, criatividade e inteligência) apenas estão modestamente relacionados.

Um autor chave para o estudo da criatividade foi Guilford, que introduziu o conceito de pensamento divergente. Guilford defendia que os pensadores divergentes são mais criativos do que os pensadores convergentes, mas notava que o pensamento divergente é apenas mais um dos inúmeros componentes da inteligência. Outro autor que recentemente concorreu para emaranhar a relação entre criatividade e inteligência é Gardner (1993 como citado em Piirto, 2004), que propõe oito tipos de inteligência: linguística, musical, lógico-matemática, espacial, cinéstico-corporal, intrapessoal, interpessoal e naturalista. A criatividade, como, aliás, a personalidade e outras variáveis humanas, está intimamente relacionada à inteligência, pelo que ela é necessária em todas as inteligências. Uma pessoa criativa é aquela que "dentro de um certo domínio, resolve problemas, populariza produtos ou coloca novas questões de tal maneira que é inicialmente considerada pouco habitual, mas que eventualmente é aceita pelo menos por um grupo cultural" (Gardner, 1993 como citado em Piirto, 2004, p. 21).

As duas concepções abordadas nos parágrafos anteriores definem, respectivamente, as ideias de que criatividade e inteligência são conceitos distintos e independentes, e de que a criatividade é uma componente da inteligência. Como salientam Sternberg e O'Hara (1999), essas são apenas duas visões possíveis, havendo defensores de outros três modos de ver a relação entre os dois conceitos: (a) criatividade e inteligência partilham atributos; (b) inteligência é uma componente da criatividade; e (c) inteligência e criatividade são a mesma coisa. Na sua notável revisão sobre o tema, os autores concluem que, até o momento, ainda não foi possível chegar a um consenso relativamente à relação entre inteligência e criatividade. Igual conclusão parece ser a extraída por Plucker e Esping (2015), após uma extensa revisão dos estudos sobre a relação entre os dois construtos.

As medidas usadas para avaliar a criatividade parecem contribuir para essa inconsistência, por isso Batey, Furnham e Safiullina (2010) obtiveram resultados tão distintos em seu estudo: quando a criatividade é avaliada a partir da fluência do pensamento divergente, há uma relação forte entre criatividade e inteligência fluida; já quando a realização criativa é avaliada a partir de medidas de autorrelato, não existe relação entre criatividade e inteligência fluida.

\section{Personalidade}

O desenvolvimento da personalidade tem impacto no potencial criativo do indivíduo (ChávezEakle et al., 2012). Os acontecimentos precoces na vida das pessoas que influenciam a construção da sua personalidade têm, igualmente, uma influência indireta (e também direta) sobre o desenvolvimento do seu potencial criativo. Por exemplo, a educação é um fator externo preponderante nesse assunto, dado o seu peso tremendo sobre a construção da personalidade durante a infância e a adolescência (ChávezEakle et al., 2012).

Em 1981, Perkins propunha seis traços das pessoas criativas: (a) tolerância face à complexidade, à desorganização e à assimetria; (b) capacidade de encontrar problemas, e de procurar perguntas desafiadoras, que conduzam a soluções criativas; (c) agilidade mental; (d) gosto pelo risco e aceitação do fracasso como parte integrante da aprendizagem e do processo criativo; (e) busca pela objetividade; e (f) motivação interior, intrínseca e satisfação pessoal pelo desafio, e prazer conferido pelo trabalho. 
Nos anos subsequentes, um elevado número de atributos da personalidade seria associado à criatividade. Morais (2001) enumera vários desses traços: predisposição para correr riscos, autoconfiança, tolerância à ambiguidade, coragem para expressar novas ideias, perseverança e resiliência.

Os estudos têm comprovado algumas dessas relações. Por exemplo, George e Zhou (2001) encontraram uma relação positiva entre abertura à experiência e comportamento criativo. Wolfradt e Pretz (2001) verificaram que a abertura à experiência e a extroversão se relacionam positivamente com criatividade. Chen e Chen (2012) evidenciaram uma relação entre abertura à experiência e personalidade criativa. Sternberg (2012) refere que a criatividade é alavancada por alguns atributos personalísticos, como a vontade de superar obstáculos, a assunção de riscos, a tolerância à ambiguidade e a autoeficácia.

Contudo, as relações encontradas nem sempre são consistentes. Por exemplo, enquanto Feist (1999) afirma que a sociabilidade e a conscienciosidade estão negativamente associadas à criatividade, Hsieh, Hsieh e Wang (2011) verificaram, em seu estudo empírico, que a conscienciosidade, a sociabilidade e a abertura à experiência têm um impacto positivo na inovação tecnológica. De igual modo, Batey et al. (2010) alertam para que, na literatura, tanto se encontra uma associação positiva quanto negativa do neuroticismo com a criatividade, dependente da medida utilizada para avaliar o construto de criatividade.

A dificuldade em estabelecer uma relação definitiva entre criatividade e personalidade pode advir de várias razões. Dentre elas, uma que se revela saliente pelas suas repercussões para a discussão sobre a própria definição de criatividade é aquela que distingue vários tipos de tarefas criativas. Assim, Dacey e Lennon (1998) demonstram uma associação entre alguns traços personalísticos e a produtividade em tarefas criativas, mormente no âmbito da geração de soluções criativas de alta qualidade em tarefas mal definidas. E Aguilar-Alonso (1996) concluiu que diferentes medidas do comportamento criativo se relacionavam com o psicoticismo e a extroversão, entre outros predicados.

Esses trabalhos demonstram que, não obstante poder afirmar-se algo sobre a personalidade criativa, um consenso pode estar difícil de conseguir, ou pode mesmo ser impossível, como advoga Sousa (2000). O autor faz notar que, apesar das inúmeras tentativas que têm sido feitas para definir a personalidade criativa, deve-se concluir que não existe um padrão que a defina, mas apenas traços que, em maior ou menor número, podem ser encontrados em indivíduos criativos, não havendo a certeza de que esses traços sejam comuns a todos os criativos. O egoísmo, a excentricidade e a instabilidade são exemplos de defeitos que podem ser melhor tolerados em termos sociais, se constituírem o lado desfavorável de um caráter destinado a grandes feitos.

\section{Atitudes e estados de humor}

Ao invés de se discutir se há indivíduos mais ou menos criativos, Kirton (1992) prefere identificar os estilos que as pessoas adotam no que se refere à criatividade, classificando-as em adaptadoras ou inovadoras. $\mathrm{O}$ estilo define a maneira como se é criativo, ou seja, o modo como se tomam decisões e se resolvem problemas em uma situação. Assim, as pessoas com um estilo adaptativo exercem as suas atividades dentro dos parâmetros definidos para a situação, concentrando-se em eficiência, consistência e precisão. As pessoas com um estilo inovador rompem paradigmas e procuram novas maneiras de fazer as coisas. Ou seja, quer os adaptativos, quer os inovadores, ambos são criativos, apenas de formas diferentes. Os adaptativos partem da questão: como posso eu fazer isto melhor?; os inovadores perguntam-se como posso eu fazer isto de forma diferente?. O Kirton Adaptors-Innovators Inventory (KAI) é o instrumento desenhado por Kirton para identificar e caracterizar os estilos criativos.

Outro autor com uma vasta obra na área de estilos de pensamento criativo é Basadur (1997; Basadur \& Hausdorf, 1996). Para Basadur, as pessoas desenvolvem estilos preferenciais de resolução criativa de problemas, e essas preferências podem acoplar-se a uma ou a várias das fases do processo criativo. À semelhança de Kirton, Basadur concebeu um inventário para rastrear os estilos criativos preferenciais das pessoas, o The Creative Problem Solving Profile (ou CPSP, na sua designação abreviada). 
Uma variável que aparenta afetar a criatividade é o estado de humor (mood, no inglês). Em uma sucessão de quatro estudos experimentais, envolvendo perto de 750 estudantes, De Dreu, Baas e Nijstad (2008) confirmam que estados de humor de ativação (e.g., felicidade, ira) induzem maior fluência e originalidade do que estados de humor de desativação (e.g., tristeza, serenidade). Relacionada ao estado de humor, a investigação que relaciona o afeto com a performance criativa tem revelado algumas inconsistências (Filipowicz, 2006): se, em alguns casos, tem-se encontrado uma associação entre criatividade e humor positivo (e.g., Amabile, Barsade, Mueller, \& Staw, 2005), em outros, a associação é com o humor negativo (e.g. George \& Zhou, 2002). Amabile, Barsade, Mueller e Staw (2005) explicam essas contradições afirmando que a relação entre criatividade e afeto negativo está mais presente em profissões que exigem um trabalho mais solitário, como as artes ou a escrita, contrariamente ao que se passa nas organizações.

Recentemente, o estudo de Rego, Sousa, Marques e Cunha (2012) mostrou que os indivíduos otimistas apresentam uma maior motivação para alcançar os seus objetivos, persistindo no sentido de ultrapassar obstáculos que possam surgir. Verificaram ainda que o afeto positivo está positivamente relacionado à criatividade, pois as emoções positivas levam as pessoas a pensarem de uma forma diferente, mais flexível e criativa. Evidenciaram também que a criatividade dos colaboradores depende da frequência com que experienciam estados de afeto positivo, mas também do peso relativo que esses estados têm sobre os estados de afeto negativo. Isso significa que um certo nível de afeto negativo é necessário para promover a criatividade dos colaboradores, pois este, conjugado com o afeto positivo, leva-os a procurarem soluções criativas ao encontrarem obstáculos na persecução dos seus objetivos. Como explicam George e Zhou (2002), quando as pessoas experienciam humor negativo, estão mais propensas a identificar problemas e falhas no seu desempenho, esforçando-se para gerar ideias novas e úteis e prestando atenção aos fatos e aos detalhes, em vez de confiarem em esquemas preexistentes, que podem conter erros. Naylor, Kim e Pettijohn (2013) vão mais longe, ao mostrar, em dois experimentos, um efeito de interação entre personalidade e estados de humor, de modo que os níveis mais elevados de criatividade têm origem em indivíduos extrovertidos com afeto positivo, mas também nos introvertidos com afeto negativo.

Em suma, como sugerem Hennessey e Amabile (2010), o humor positivo conduz tendencialmente à expansão, ao pensamento divergente e à geração de novas ideias; o humor negativo indica, sobretudo, que algo não está bem e impele os colaboradores a tentarem melhorar a situação com ideias criativas. Essa relação complexa entre os fenômenos sugere que a criatividade pode advir simultaneamente de humores positivos e negativos, o que lembra a necessidade de mais investigação sobre o assunto.

\section{Expertise (conhecimento)}

Criatividade é sinônimo de criação de conhecimento, que se processa via seleção de ideias, sua edição, marketing e aceitação pela cultura vigente (Chiu \& Kwan, 2010). A relação entre conhecimento e criatividade reflete, aliás, uma tensão entre esses dois poderosos motores do progresso. Como enuncia Weisberg (1999), por definição, criatividade é ir para além do conhecimento, mas o conhecimento deve ser a base para se ser criativo. A resolução dessa antinomia passa pela definição pouco estruturada, ou frouxa, da relação entre as bases do conhecimento que impulsionam a criatividade, por um lado, e as ideias criativas que vão superar o saber que as originou, por outro.

Para se compreender a acepção anterior, tome-se o exemplo seguinte: para se produzir algo de verdadeiramente novo em um qualquer domínio de trabalho, uma pessoa deve primeiro conquistar um elevado nível de expertise; por outro lado, demasiada erudição em um campo do conhecimento pode ter um efeito nefasto para se responder de forma criativa, produzindo uma resposta estereotipada ou inconscientemente defensiva de estatutos e poderes adquiridos.

Weisberg (1999) elucida que, não obstante a popularidade dessa perspectiva da tensão entre conhecimento e criatividade, existem autores que defendem a existência de uma relação positiva entre conhecimento e criatividade. Por exemplo, Hayes (1990) procurou determinar o tempo necessário para se alcançar o nível máximo de mestria em uma arte que requer criatividade (e.g., composição musical, 
pintura, poesia). Os resultados, constantes nas artes analisadas, mostram que são precisos, em média, 10 anos para se conseguir produzir algo realmente diferente e criativo. Gardner (1993 como citado em Piirto, 2004) reporta resultados semelhantes em vários campos científicos, como aqueles liderados por Freud, Einstein ou Gandhi.

Glăveanu (2010a) disseca a problemática, concluindo que a literatura tem representado a relação entre criatividade e conhecimento como uma curva em U invertido, ou seja, o conhecimento é importante para a criatividade até um nível ótimo, começando depois a perder relevância. Essa relação complexa entre conhecimento acumulado e criatividade afigura-se ter sentido: parece com efeito ser imprescindível aprofundar e imergir totalmente em uma área do saber ou das artes, antes de se conseguir atingir um patamar em que se consegue romper criativamente com o conhecimento existente.

A ligação entre criatividade e conhecimento torna-se ainda mais premente se a ela se adicionar um parente próximo e com uma importância capital nas modernas organizações: a inovação. O estudo de Medina, Cabrales e Cabrera (2011) demonstrou que a singularidade do capital humano tem um impacto positivo na inovação da organização. Ora, segundo os autores, a singularidade do capital humano é apenas possível pelo conhecimento acumulado, pelas suas competências e pela criatividade impressa na atividade e no trabalho. De forma similar, Hsieh et al. (2011) revelaram que a partilha, aquisição, acumulação e aplicação de conhecimento influencia positivamente a capacidade de inovação. Esses e outros trabalhos comprovam que a inovação, o conhecimento e a criatividade tecem entre si complexas relações que afetam os resultados intermédios e finais em ambientes de trabalho.

\section{Motivação}

A questão basilar nos estudos sobre motivação é o que origina o comportamento humano? Deste modo, nada mais natural do que transpor essa questão para o estudo da criatividade: o que origina a criatividade?. Também com despretensão deve, assim, ser encarada a tentativa de relacionar criatividade e motivação: o que motiva a criatividade?.

Anos de pesquisa sobre o assunto conduzem, segundo Collins e Amabile (1999), à conclusão de que a criatividade é fortemente afetada pela motivação intrínseca (ver também Hennessey, 2010), enquanto é deteriorada pela motivação extrínseca. Utilizando os trabalhos de Crutchfield (1962 como citado em Collins \& Amabile, 1999) como referência principal, as duas autoras explicam que o primeiro tipo de motivação caracteriza-se por um elevado envolvimento com o conteúdo da tarefa, em que a pessoa é guiada essencialmente pelo valor intrínseco associado à realização de uma tarefa e pela paixão e pelo entusiasmo de resolvê-la. A motivação extrínseca é centrada no ego, ou seja, a concretização da tarefa tem como objetivo atingir um qualquer outro fim, que não propriamente o de se ser criativo na tarefa. A motivação intrínseca está centralizada no alcance da tarefa; a extrínseca, em alguma recompensa ou reconhecimento ulterior.

Essa linha de raciocínio constitui a espinha dorsal daquele que é provavelmente um dos trabalhos que mais impacto tem causado nos últimos anos, sobre a relação entre motivação e criatividade. Da autoria de Amabile (1997, 1996, 1988), o modelo inclui três componentes: capacidades criativas, expertise e motivação. O domínio dos conhecimentos e as capacidades para o pensamento criativo constituem a base de trabalho de um indivíduo, os seus recursos naturais. Mas é a motivação que vai determinar o que eles serão realmente capazes de fazer. É necessário que o sujeito, ou o grupo de trabalho, esteja intrinsecamente motivado, pois apenas assim serão capazes de orientar os seus conhecimentos e capacidades para serem criativos.

Para além de Amabile, outros têm teorizado sobre motivação e criatividade. Por exemplo, Liu, Chen e Yao (2011), em um estudo realizado na China, analisaram a forma como a paixão harmoniosa (no original: harmonious passion, um tipo de motivação intrínseca que conduz à absorção plena na tarefa) interage com a autonomia para influenciar a criatividade. Os autores mostraram que a paixão harmoniosa modera a relação entre criatividade e a autonomia individual, grupal e organizacional. De igual modo, Csikszentmihalyi (1990) havia já popularizado o termo flow, um estado de profunda absorção quando se está realizando uma tarefa, cuja concretização dá ao sujeito um prazer intrínseco 
profundo. Moneta (2012) confirmou que a oportunidade para a criatividade no trabalho modera (exacerba) a relação positiva entre motivação intrínseca (traço) e a probabilidade de experienciar flow no local de trabalho. Conclui ainda que a interação entre a motivação intrínseca e a oportunidade para a criatividade no trabalho predizem o flow no trabalho.

Por fim, é importante referir que alguns autores têm chamado a atenção para o papel da motivação extrínseca (George, 2007). Burroughs, Dahl, Moreau, Chattopadhyay e Gorn (2011) mostraram que, quando as recompensas são combinadas com formação adequada, podem aumentar a criatividade. A formação, neste caso, funciona como um fator de motivação intrínseca, sugerindo que a motivação extrínseca conciliada com a intrínseca pode promover a criatividade. Outros autores (e.g., Deci, Ryan, \& Williams, 1996) defendem a teoria de que a motivação extrínseca, como o sistema de compensação, pode fomentar a criatividade, algo que foi empiricamente atestado por Selart, Nordström, Kuvaas e Takemura (2008).

\section{Conclusão}

Os primeiros estudos sobre os gênios criativos terão influenciado as abordagens iniciais do estudo da criatividade, no sentido em que orientaram a investigação para a busca do perfil do indivíduo criativo. $\mathrm{O}$ chamamento para encontrar tal perfil foi, todavia, progressivamente abandonado, à medida que se tomava consciência da infinita combinação e interação de variáveis que intervêm no processo de criação. A partir de meados do Século XX, o novo paradigma de pensamento, consubstanciado na ideia do individualismo por oposição ao holismo (Dumont, 1985), conduz a uma definição do "indivíduo-nomundo", cujo valor depende mais do que mostra perante outros e menos do que aquilo que é "fora-domundo" (nas expressões de Dumont, 1985, p. 37). A hierarquização social ocorre então pelo valor dos produtos humanos e não tanto pela posição na hierarquia, numa afirmação dos princípios da igualdade e liberdade. Na criatividade, isso significou a entrada da noção de contexto na literatura, imiscuindo-se na própria definição do conceito (atribuída a Stein), e que até hoje domina o pensamento sobre o tema. Com efeito, a introdução da noção de contexto viria a complexificar os estudos sobre o fenômeno, desenvolvendo-se e aceitando-se o argumento de que não se pode compreender o indivíduo criativo sem atender ao contexto em que este está inserido. O contexto passou a ser a identidade da criatividade. Sendo um fenômeno complexo, é pois lógico afirmar que a criatividade tem que ser estudada como um processo complexo e multifacetado, que se desenvolve em torno da esfera pessoal, mas também social e cultural em que o indivíduo está inserido.

Como foi mostrado no presente texto, as significações de contexto são várias, e nem sempre usadas de forma harmônica na literatura. Incluem as noções de valor e utilidade para algo ou alguém, de entidade que valida e sanciona a produção criativa (e.g. noção de campo, em Csikszentmihalyi, 1996), de fatores promotores/inibidores externas à pessoa (e.g. Alencar \& Bruno-Faria, 1997), e de agente coprodutor no processo criativo (e.g. Glăveanu, 2010b). As duas primeiras significações reportam-se a atributos avaliativos expressos por entidades externas ao indivíduo criador. As duas segundas referemse a atributos ativos de entidades exteriores, como se essas entidades fossem centrais na produção criativa, relegando para segundo plano o principal agente da produção criativa, isto é, o indivíduo. Neste texto, recuperou-se o argumento da individualidade em contexto, sobretudo nas duas segundas significações. Por outras palavras, intentou-se recuperar o argumento que os indivíduos criativos sãono, não no sentido clássico de gênio, mas na perspectiva de que as pessoas criativas possuem capacidades, traços ou atributos que são distintivos de pessoas menos criativas, e que tais características possuem um valor intrínseco, relativamente independente do contexto em que se expressam.

Esperou-se, deste modo, relançar a discussão sobre os fatores individuais que influenciam a criatividade e a produção criativa, no pressuposto de que não obstante a sua marcada importância, o contexto nem sempre importa ou influencia na geração de novas ideias. Esse pensamento em que o indivíduo é a figura e o contexto é o fundo é, quanto aos autores deste texto, mais apropriado para desenvolver ambientes organizacionais que permitam resgatar o potencial de produtos criativos sem um 
valor e utilidade aparentes ou imediatamente identificáveis. Talvez assim se evitem casos em que o gênio criativo teve que esperar décadas ou séculos por melhores condições de reconhecimento social, como sucedeu com Bach ou Mozart.

Pelo exposto, este texto encerra implicações teóricas e práticas para o estudo e a gestão da criatividade. A implicação teórica mais relevante remete para a própria definição de criatividade ou, talvez de forma mais precisa, para o papel da noção de contexto na definição de criatividade. Assim, definir criatividade como algo útil e que acrescenta valor para alguma entidade é profundamente redutor, não apenas do ponto de vista teórico, mas também prático. Algo original que é gerado no aqui e no agora, mas que, devido à dimensão sancionadora do contexto, não é julgado original, poderá levar, no acolá ou no futuro, a novas e inesperadas vias de desenvolvimento. Deste modo, parece muito mais profícuo avançar na (re)definição de criatividade no sentido sugerido por Glăveanu (2010b), em que o contexto é um agente co-produtor no processo criativo, mas realçando o papel capital que têm outros agentes, do foro individual. O presente texto incentivou a (re)tomar a ideia de que esses agentes individuais são centrais no pensamento sobre criatividade.

Uma segunda implicação remete para a pesquisa do papel ativo que tem o indivíduo na construção subjetiva do seu contexto envolvente e subsequente motivação para ser mais ou menos criativo. Esta linha de pesquisa poderá ajudar a responder a questões complexas, quais sejam: (a) por que razão é que, num mesmo contexto, alguns indivíduos são mais criativos do que outros?; e (b) de que forma é que os mesmos fatores contextuais podem ser percebidos como bloqueadores ou como estimulantes da criatividade?

Por fim, no que concerne à gestão da criatividade, a principal implicação reside em repensar os termos valor e utilidade quando se analisa algum tipo de produção original e criativa. Valor e utilidade são atributos usados para julgar algo contra um referencial conhecido e aceite. À luz da moderna concepção de criatividade, esses dois atributos são ainda responsáveis por excluir indivíduos ou seus produtos originais, por não se enquadrarem no paradigma dominante. Desse modo, o presente texto desafia a repensar os contextos existentes de escrutínio e avaliação de potenciais criativos que assentem unicamente no valor e na utilidade de algo, e a integrar outros atributos e/ou a repensar os referenciais contra os quais se julga algo como útil e com valor. O resultado prático poderá ser uma expansão de tais contextos avaliativos da criatividade, em que o contexto deixe de funcionar como um obstáculo ao desenvolvimento de criações que divirjam do paradigma dominante, e passe, ao invés, a estimular esse mesmo desenvolvimento.

\section{Referências}

Aggarwal, Y., \& Bhatia, N. (2011). Creativity and innovation in management: a fuel for growth. International Journal of Multidisciplinary Research, 1(5), 288-296.

Aguilar-Alonso, A. (1996). Personality and creativity. Personality Individual Differences, 21(6), 959969. http://dx.doi.org/10.1016/S0191-8869(96)00162-6

Albert, R. S., \& Runco, M. A. (1999). A history of research on creativity. In R. J. Sternberg (Ed.), Handbook of creativity (pp. 16-31), New York: Cambridge University. http://dx.doi.org/10.1017/CBO9780511807916.004

Alencar, E. M. L. S., \& Bruno-Faria, M. F. (1997). Characteristics of an organizational environment which stimulate and inhibit creativity. Journal of Creative Behaviour, 31(4), 271-281. http://dx.doi.org/10.1002/j.2162-6057.1997.tb00799.x

Alencar, E. M. L. S., \& Fleith, D. S. (2003). Criatividade: múltiplas perspectivas. Brasília: Universidade de Brasília. 
Almagro, J. (1986). Família y education. In J. Mayor (Org.), Sociologia y psicologia social de la education (pp. 445-469). Madrid: Ediciones Anaya.

Amabile, T. M. (1988). A model of creativity and innovation in organizations. Research in Organizational Behaviour, 10, 123-167.

Amabile, T. M. (1996). Creativity in context. Colorado: Westview Press.

Amabile, T. M. (1997). Entrepreneurial creativity through motivational synergy. Journal of Creative Behaviour, 31(1), 18-26. http://dx.doi.org/10.1002/j.2162-6057.1997.tb00778.x

Amabile, T. M., Barsade, S. G., Mueller, J. S., \& Staw, B. M. (2005). Affect and creativity at work. Administrative Science Quarterly, 50(3), 367-403. http://dx.doi.org/10.2189/asqu.2005.50.3.367

Baer, J. (2012). Domain specificity and the limits of creativity theory. The Journal of Creative Behavior, 46(1), 16-29. http://dx.doi.org/10.1002/jocb.002

Basadur, M. (1997). Organizational development interventions for enhancing creativity in the workplace. Journal of Creative Behaviour, 31(1), 59-72. http://dx.doi.org/10.1002/j.21626057.1997.tb00781.x

Basadur, M., \& Hausdorf, P. A. (1996). Measuring divergent thinking attitudes related to creative problem solving and innovation management. Creativity Research Journal, 5(3), 22-47. http://dx.doi.org/10.1207/s15326934crj0901_3

Batey, M., Furnham, A., \& Safiullina, X. (2010). Intelligence, general knowledge and personality as predictors of creativity. Learning and Individual Differences, 20(5), 532-535. http://dx.doi.org/10.1016/j.lindif.2010.04.008

Bento, J. (2013). Dealing with disruption adapting to survive and thrive. Annual Global CEO Survey, 16. Recuperado de http://www.pwc.com/gx/en/ceo-survey/2013/assets/pwc-16th-global-ceosurvey_jan-2013.pdf

Bowers, K. S., Regehr, G., Balthazard, C., \& Parker, K. (1990). Intuition in the context of discovery. Cognitive Psychology, 22(1), 72-110. http://dx.doi.org/10.1016/0010-0285(90)90004-N

Burroughs, J. E., Dahl, D. W., Moreau, C. P., Chattopadhyay, A., \& Gorn, G. J. (2011). Facilitating and rewarding creativity during new product development. Journal of Marketing, 75(4), 53-67. http://dx.doi.org/10.1509/jmkg.75.4.53

Cain, S. (2012). Quiet: the power of introverts in a world that can't stop talking. New York: Random House.

Chávez-Eakle, R. A., Eakle, A. J., \& Cruz-Fuentes, C. (2012). The multiple relations between creativity and personality. Creativity Research Journal, 24(1), 76-82. http://dx.doi.org/10.1080/10400419.2012.649233

Chen, J.-K., \& Chen, I.-S. (2012). Creative-oriented personality, creativity improvement, and innovation level enhancement. Quality \& Quantity: International Journal of Methodology, 46(5), 1625-1642. http://dx.doi.org/10.1007/s11135-011-9471-8

Chiu, C., \& Kwan L. (2010). Culture and creativity: a process model. Management and Organization Review, 6(3), 447-461. http://dx.doi.org/10.1111/j.1740-8784.2010.00194.x

Claxton, G. (1998). Investigating human intuition: knowing without knowing why. The Psychologist, 11(5), 217-220. http://dx.doi.org/10.1002/brb3.420 
Coelho, F., Augusto, M., \& Lages, L. F. (2011). Contextual factors and the creativity of frontline employees: the mediating effects of role stress and intrinsic motivation. Journal of Retailing, 87(1), 31-45. http://dx.doi.org/10.1016/j.jretai.2010.11.004

Collins, M. A., \& Amabile, T. M. (1999). Motivation and creativity. In R. J. Sternberg (Ed.), Handbook of creativity (pp. 297-312). New York: Cambridge University. http://dx.doi.org/10.1017/CBO9780511807916.017

Csikszentmihalyi, M. (1990). Flow: the psychology of optimal experience. New York: Harper \& Row.

Csikszentmihalyi, M. (1996). Creativity. New York: HarperCollins.

Cunha, M. P. (2002). All that jazz: três aplicações do conceito de improvisação organizacional. Revista de Administração de Empresas, 42(3), 36-42. http://dx.doi.org/10.1590/S003475902002000300004

Dacey, J., \& Lennon, K. (1998). Understanding creativity. San Francisco: Jossey-Bass Publishers.

Deci, E. L., Ryan, R. M., \& Williams, G. C. (1996). Need satisfaction and the self-regulation of learning. Learning \& Individual Differences, 8(3), 165-184. http://dx.doi.org/10.1016/S10416080(96)90013-8

De Dreu, C. K. W., Baas, M., \& Nijstad, B. A. (2008). Hedonic tone and activation level in the moodcreativity link: toward a dual pathway to creativity model. Journal of Personality and Social Psychology, 94(5), 739-756. http://dx.doi.org/10.1037/0022-3514.94.5.739

Dul, J., \& Ceylan, C. (2011). Work environments for employee creativity. Ergonomics, 54(1), 12-20. http://dx.doi.org/10.1080/00140139.2010.542833

Dumont, L. (1985). O individualismo. Uma perspectiva antropológica da ideologia moderna. Rio de Janeiro: Rocco.

Ekvall, G. (1996). Organizational climate for creativity and innovation. European Journal of Work and Organizational Psychology, 5(1), 105-123. http://dx.doi.org/10.1080/13594329608414845

Elias, N. (1991). Mozart. Sociologia de um gênio. Rio de Janeiro: Zahar.

Feist, G. J. (1999). The influence of personality on artistic and scientific creativity. In R. J. Sternberg (Ed.), Handbook of creativity (pp. 273-296). New York: Cambridge University Press. http://dx.doi.org/10.1017/CBO9780511807916.016

Feldman, D. H. (1999). The development of creativity. In R. J. Sternberg (Ed.), Handbook of creativity (pp. 169-186). New York: Cambridge University Press. http://dx.doi.org/10.1017/CBO9780511807916.011

Filipowicz, A. (2006). From positive affect to creativity: the surprising role of surprise. Creativity Research Journal, 18(2), 141-152. http://dx.doi.org/10.1207/s15326934crj1802_2

Frankl, V. (2004). Man's search for meaning. London: Rider.

Friedel, R. (1992). Perspiration in perspective. In R. J. Weber \& D. N. Perkins (Eds.), Inventive minds: creativity in technology (pp. 11-29). Oxford: Oxford University Press.

Furnham, A., \& Bachtiar, P. (2008). Personality and intelligence as predictors of creativity. Personality and Individual Differences, 45(7), 613-617. http://dx.doi.org/10.1016/j.paid.2008.06.023

George, J. M. (2007). Creativity in organizations. The Academy of Management Annals, 1(1), 439-477 http://dx.doi.org/10.1080/078559814 
George, J. M., \& Zhou, J. (2001). When openness to experience and conscientiousness are related to creative behavior: an interactional approach. Journal of Applied Psychology, 86(3), 513-524. http://dx.doi.org/10.1037/0021-9010.86.3.513

George, J. M., \& Zhou, J. (2002). Understanding when bad moods foster creativity and good ones don't: the role of context and clarity of feelings. Journal of Applied Psychology, 87(4), 687-697. http://dx.doi.org/10.1037/0021-9010.87.4.687

Glăveanu, V. P. (2010b). Creativity as cultural participation. Journal for the Theory of Social Behaviour, 4l(1), 48-67. http://dx.doi.org/10.1111/j.1468-5914.2010.00445.x

Glăveanu, V. P. (2010a). Principles for a cultural psychology of creativity. Culture \& Psychology, 16(2), 147-163. http://dx.doi.org/10.1177/1354067X10361394

Gomes, J. F. S., Rodrigues, A. F., \& Veloso, A. (2015). Creativity at work: the role of context. In H. Shipton, P. Budhwar, P. Sparrow, P., \& A. Brown (Eds.), Human resource management, innovation and performance (pp. 282-297). London: Palgrave Macmillan. http://dx.doi.org/10.1057/9781137465191_18

Hayes, J. R. (1990). Cognitive processes in creativity [Occasional Paper $n^{\circ}$ 18]. Recuperado de http://www.nwp.org/cs/public/download/nwp_file/41/OP18.pdf?x-r=pcfile_d

Hennessey, B. A. (2010). The creativity-motivation connection. In J. C. Kaufman \& R. J. Sternberg (Eds.), Cambridge handbook of creativity (pp. 342-365). New York: Cambridge University Press http://dx.doi.org/10.1017/CBO9780511763205.022

Hennessey, B. A., \& Amabile, T. M. (2010). Creativity. Annual Review of Psychology, 61, 569-598 http://dx.doi.org/10.1146/annurev.psych.093008.100416

Hsieh, H.-L., Hsieh, J.-R., \& Wang, I.-L. (2011). Linking personality and innovation: the role of knowledge management. World Transactions on Engineering and Technology Education, 9(1), 38-44. http://dx.doi.org/10.1111/apps.12024

Hunter, S. T., Bedell, K. E., \& Mumford, M. D. (2007). Climate for creativity: a quantitative review. Creativity Research Journal, 19(1), 69-90. http://dx.doi.org/10.1080/10400410709336883

Isaksen, S. G., \& Lauer, K. J. (2002). The climate for creativity and change in teams. Creativity \& Innovation Management, 11(1), 74-86. http://dx.doi.org/10.1111/1467-8691.00238

Joo, B.-K., McLean, G. N., \& Yang, B. (2013). Creativity and human resource development: an integrative literature review and a conceptual framework for future research. Human Resource Development Review, 12(4), 390-421. http://dx.doi.org/10.1177/1534484313481462

Kaufman, J. C. (2005). The door that leads into madness: Eastern European poets and mental illness. Creativity Research Journal, 17(1), 99-103. http://dx.doi.org/10.1207/s15326934crj1701_8

Kirton, M. J. (1992). Adaptors and innovators: problem-solvers in organizations. In S. S. Gryskiewicz \& D. A. Hills (Eds.), Readings in innovation (pp. 45-67). Greensboro, NC: Center for Creative Leadership.

Ko, Y., \& Kim, J. (2008). Scientific geniuses' psychopathology as a moderator in the relation between creative contribution types and eminence. Creativity Research Journal, 20(3), 251-261. http://dx.doi.org/10.1080/10400410802278677

Kyaga, S., Landén, M., Boman, M., Hultman, C. M., Långström, N., \& Lichtenstein, P. (2012). Mental illness, suicide and creativity: 40-year prospective total population study. Journal of Psychiatric Research, 47(1), 83-90. http://dx.doi.org/10.1016/j.jpsychires.2012.09.010 
Landry, C. (2000). The creative city: a toolkit for urban innovators. London: Earthscan Publications.

Liu, D., Chen, X.-P., \& Yao, X. (2011). From autonomy to creativity: a multilevel investigation of the mediating role of harmonious passion. Journal of Applied Psychology, 96(2), 294-309. http://dx.doi.org/10.1037/a0021294

Lubart, T. I. (1999). Creativity across cultures. In R. J. Sternberg (Ed.), Handbook of creativity (pp. 339350). New York: Cambridge University Press. http://dx.doi.org/10.1017/CBO9780511807916.019

Maker, C. J., Jo, S., \& Muammar, O. M. (2008). Development of creativity: the influence of varying levels of implementation of the DISCOVER curriculum model, a non-traditional pedagogical $\begin{array}{llll}\text { approach. Learning \& Individual Differences, } & 18(4), & 402-417 .\end{array}$ http://dx.doi.org/10.1016/j.lindif.2008.03.003

Martindale, C. (1990). The clockwork muse: the predictability of artistic change. New York: Basic Books.

Medina, C. C., Cabrales, Á. L., \& Cabrera, R. V. (2011). Leveraging the innovative performance of human capital through HRM and social capital. International Journal of Human Resources Management, 22(4), 807-828. http://dx.doi.org/10.1037/t32117-000

Menger, P.-M. (2014). The economics of creativity. Art and achievement under uncertainty. MA: Harvard University Press.

Moneta, G. B. (2012). Opportunity for creativity in the job as a moderator of the relation between trait intrinsic motivation and flow in work. Motivation and Emotion, 36(4), 491-503. http://dx.doi.org/10.1037/t01422-000

Morais, F. (2001). Definição e avaliação da criatividade. Braga: Universidade do Minho.

Naylor, P. D., Kim, J.-H., \& Pettijohn, T. F., III (2013). The role of mood and personality type on creativity. Journal of Psychological Research, 18(4), 148-156. http://dx.doi.org/10.1037/t07016000

Perkins, D. N. (1981). The mind's best work. Cambridge, Mass: Harvard University Press.

Piirto, J. (2004). Understanding creativity. Scottsdale: Great Potential Press.

Plucker, J. S., \& Esping, A. (2015). Intelligence and creativity: a complex but important relationship. Asia Pacific Education Review, 16(2), 153-159. http://dx.doi.org/10.1007/s12564-015-9374-9

Proudfoot, D., Kay, A. C., \& Koval, K. Z. (2015). A gender bias in the attribution of creativity: archival and experimental evidence for the perceived association between masculinity and creative thinking. Psychological Science, 26(11), 1751-1761. http://dx.doi.org/10.1177/0956797615598739

Rego, A., Sousa, F., Marques, S., \& Cunha, M. P. C. (2012). Optimism predicting employees' creativity: the mediating role of positive affect and the positivity ratio. European Journal of Work and Organizational Psychology, 21(2), 244-270. http://dx.doi.org/10.1002/ job.714

Robinson, K. (2001). Unlocking creativity: a strategy for development. Belfast: Department of Culture, Arts, and Leisure.

Robinson, K. (2006). Do schools kill creativity?. Recuperado em maio 12, 2016 de http://www.ted.com/index.php/talks/ken_robinson_says_schools_kill_creativity.html 
Runco, M. A., \& Jaeger, G. J. (2012). The standard definition of creativity. Creativity Research Journal, 24(1), 92-96. http://dx.doi.org/10.1080/10400419.2012.650092

Runco, M. A., \& Pritzker, S. (Eds.). (1999). Encyclopaedia of creativity (Vol. 2). San Diego: Academic Press.

Ryhammar, L., \& Brolin, C. (1999). Creativity research: historical considerations and main lines of development. Scandinavian Journal of Educational Research, 43(3), 259-273. http://dx.doi.org/10.1080/0031383990430303

Selart, M., Nordström, T., Kuvaas, B., \& Takemura, K. (2008). Effects of rewards on self-regulation, intrinsic motivation and creativity. Scandinavian Journal of Educational Research, 52(5), 439458. http://dx.doi.org/10.1080/00313830802346314

Silvia, P. J. (2008). Creativity and intelligence revisited: a latent variable analysis of Wallach and Kogan $\begin{array}{llll}\text { (1965). Creativity } & \text { Research 34-39. }\end{array}$ http://dx.doi.org/10.1080/10400410701841807

Simmel, G. (1998). O dinheiro na cultura moderna. In J. Souza \& B. Oëlze (Orgs.), Simmel e a modernidade (pp. 23-40), Brasília: UNB.

Simonton, D. K. (1999). Creativity from a historiometric perspective. In R. J. Sternberg (Ed.), Handbook of creativity (pp. 116-133). New York: Cambridge University Press. http://dx.doi.org/10.1017/CBO9780511807916.008

Sousa, F. (2000). A criatividade como disciplina científica (2a ed.). Santiago de Compostela: Imprenta Universitária.

Sternberg, R. J. (2012). The assessment of creativity: an investment-based approach. Creativity Research Journal, 24(1), 3-12. http://dx.doi.org/10.1080/10400419.2012.652925

Sternberg, R. J., \& Lubart, T. I. (1999). The concept of creativity: prospects and paradigms. In R. J. Sternberg (Ed.), Handbook of creativity (pp. 3-9). New York: Cambridge University Press. http://dx.doi.org/10.1017/CBO9780511807916.003

Sternberg, R. J., \& O’Hara, L. A. (1999). Creativity and intelligence. In R. J. Sternberg (Ed.), Handbook of creativity (pp. 251-272). New York: Cambridge University Press. http://dx.doi.org/10.1017/CBO9780511807916.015

Stolcke, V. (2001). Gloria o maldición del individualismo moderno según Louis Dumont. Revista de Antropologia, 44(2), 7-37. http://dx.doi.org/10.1590/S0034-77012001000200001

Stoltzfus, G., Nibbelink, B. L., Vredenburg, D., \& Thyrum, E. (2011). Gender, gender role, and

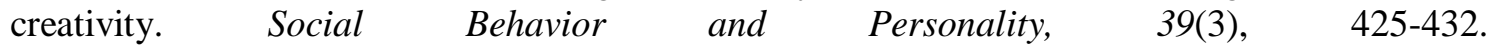
http://dx.doi.org/10.2224/sbp.2011.39.3.425

Weisberg, R. W. (1999). Creativity and knowledge: a challenge to theories. In R. J. Sternberg (Ed.), Handbook of creativity (pp. 226-250). New York: Cambridge University Press. http://dx.doi.org/10.1017/CBO9780511807916.01

Wolfradt, U., \& Pretz, J. E. (2001). Individual differences in creativity: personality, story writing, and hobbies. European Journal of Personality, 15(4), 297-310. http://dx.doi.org/10.1002/per.409 


\section{Dados dos Autores}

Jorge Filipe da Silva Gomes

Rua do Quelhas, 6, 1249-078, Lisboa, Portugal. E-mail: jorgegomes@iseg.ulisboa.pt

Ana Filipa Rodrigues

Campus de Gualtar, 4710-057, Braga, Portugal. E-mail: filipa.c.rodrigues@gmail.com

Ana Veloso

Campus de Gualtar, 4710-057, Braga, Portugal. E-mail: alveloso@psi.uminho.pt 